\title{
O FAZER PEDAGÓGICO EM CONTEXTO DE INCLUSÃO: ESTRATÉGIAS, AÇÕES E RESULTADOS
}

\author{
EL HACER PEDAGÓGICO EN CONTEXTO DE INCLUSIÓN: ESTRATEGIAS, \\ ACCIONES Y RESULTADOS
}

\section{THE PEDAGOGICAL PRACTICES IN INCLUSIVE CONTEXT: STRATEGIES, ACTIONS AND RESULTS}

\author{
Marco Antonio Melo FRANCO ${ }^{1}$ \\ Paloma Roberta Euzebio RODRIGUES ${ }^{2}$
}

RESUMO: A investigação aqui proposta busca ir além do debate teórico sobre a inserção e a inclusão da criança no âmbito educacional. Ela volta-se para o trabalho pedagógico, em sala de aula, com a criança deficiente, no caso, a criança com paralisia cerebral. Trata-se de uma abordagem qualitativa que adota a pesquisa-ação como forma de compreender a realidade investigada e nela intervir, conjuntamente com os atores desse processo. Foi selecionada uma escola que possui no seu quadro discente crianças com paralisia cerebral. Acompanhou-se semanalmente, ao longo do período letivo, o processo de ensino e aprendizagem como forma de apropriação das rotinas, possibilitando assim, analisar, intervir e construir novas práticas pedagógicas, em conjunto com os sujeitos envolvidos. Como resultado, identificamos a construção, pelos docentes, de um olhar diferente sobre o processo de aprendizagem das crianças: a adoção de estratégias pedagógicas que consideram a individualidade dos sujeitos sem perder a dimensão do coletivo. Foram adotadas estratégias como a economia de escrita, reorganização dos espaços, mudança na forma de participação, adaptação curricular e de atividades, entre outras. Além disso, observamos um movimento conjunto dos profissionais da escola na implementação de ações que melhor acolham as crianças com deficiência.

PALAVRAS-CHAVE: Inclusão. Prática pedagógica. Ensino-aprendizagem

RESUMEN: La investigación que se propone aquí busca ir más allá del debate teórico sobre la inserción y la inclusión del niño el en ámbito educacional. Ella se vuelve para el trabajo pedagógico en sala de clases con niños discapacitados, en este caso, con niños con parálisis cerebral. Se trata de un abordaje cualitativo que adopta la investigación-acción como forma de comprender la realidad que se investiga y en ella intervenir, en conjunto con los actores de ese proceso. Fue seleccionada una escuela que posee entre su alumnado niños con parálisis cerebral. Se observó semanalmente, a lo largo del período lectivo, el proceso de enseñanza y aprendizaje como forma de

1, Professor Adjunto do Departamento de Educação da Universidade Federal de Ouro Preto. Doutor em Ciências da Saúde. Pedagogo, Mestre em Educação. <http://orcid.org/0000-0002-0159-4109>. Email: mamf.franco@gmail.com

2 Mestranda em Educação pela Universidade Federal de Alfenas. <http://orcid.org/0000-0001-81861985>. Email: palomarodrigues1991@yahoo.com.br 
apropiación de las rutinas posibilitando así, analizar, intervenir y construir nuevas prácticas pedagógicas, en conjunto con los sujetos involucrados. Como resultado identificamos la construcción, por los docentes, de una mirada diferente sobre el proceso de aprendizaje de esos niños; la adopción de estrategias pedagógicas que consideran la individualidad de los sujetos sin perder la dimensión del colectivo. Fueron adoptadas estrategias como la "economía de escrita", reorganización de los espacios, cambios en la forma de participación, adaptación curricular y de actividades, entre otras. Además, observamos un movimiento conjunto de los profesionales de la escuela en la implementación de acciones que mejor acojan a los niños discapacitados.

PALABRA CLAVE: Inclusión. Práctica pedagógica. Enseñanza-aprendizaje

ABSTRACT: This research seeks to go beyond the theoretical debate on the integration and inclusion of children with disability. It addresses pedagogical work in the classroom, with the disabled child, in this case, the child with cerebral palsy. This is a qualitative approach and action research that aims to understand the reality investigated and it intervene. Participates in the research a public school that has students with cerebral palsy. The classes were followed weekly during the school year, in order to understand and analyze the process of teaching and learning. In addition, we attempted to intervene and build new teaching practices with teachers. As a result we identified the adoption of pedagogical strategies that consider the individuality of the subjects and their participation in the school community. Strategies were adopted as written economy, reorganization of spaces, change in the form of participation, curriculum adaptation, and adaptation activities, among others.

KEYWORDS: Social inclusion. Pedagogical practice. Teaching and learning

\section{Introdução}

Temos presenciado, ao longo das últimas décadas, o crescente movimento de inclusão escolar. Trata-se de um movimento mundial com repercussões importantes. A noção de escola inclusiva ganha força com a Declaração de Salamanca (1994), que a compreende como o processo de inclusão de indivíduos com necessidades educacionais especiais ou de distúrbios de aprendizagem na rede regular de ensino em todos os seus níveis. Eles devem ser acomodados dentro de uma pedagogia que atenda às suas necessidades e demandas.

Esse movimento surge como forma de romper com o paradigma até então predominante. O pensamento que socialmente imperou trazia em seu cerne o ideal de padronização e de homogeneização do ensino e, por conseguinte, dos ensinados. Essa concepção foi construída e historicamente legitimada pela concepção de modernidade e 
implicou em atitudes de exclusão daqueles que fugiam aos padrões de normalidade (SILVA, 2005).

A emergência de novas demandas sociais concomitantemente com as mudanças dos modelos socioeconômicos mundiais, bem como com o avanço do pensamento intelectual nas últimas duas décadas, colaborou para o repensar do processo educacional e da necessidade de se construir novos modelos que atendam às demandas sociais de forma mais ampla. Nesse contexto, a perspectiva de uma sociedade mais inclusiva e, consequentemente, de uma educação menos excludente, ganha a pauta nas políticas públicas em governos mundiais.

Considerando esse cenário, o estudo aqui apresentado objetivou observar e analisar as práticas docentes no ensino regular em relação à inclusão de crianças com paralisia cerebral. Trata-se de uma proposta investigativa que observa e intervém nas práticas cristalizadas pela escola buscando construir estratégias pedagógicas e um novo cenário no processo de ensino e aprendizagem da criança deficiente.

\section{Entre o normal e o patológico}

A discussão sobre o normal e o patológico não se limita somente ao campo biológico e médico. Ela é fundamental para que possamos compreender os processos de constituição de classes especiais educacionais e a sua contribuição para o trabalho pedagógico atual, em escolas regulares. Estudos como os de Silveira Bueno (2004) contribuem para tal compreensão, uma vez que polemizam as dicotomias existentes entre "Educação especial e Educação regular; Deficiência e normalidade; Integração e segregação social" (SILVEIRA BUENO, 2004, p. 23). O autor também ressalta que tal dicotomia não contribuiu para a superação das dificuldades de escolarização e integração social de crianças com deficiências.

Institucionalizada no final do século XVIII e início do século XIX, a educação de crianças deficientes surge "no conjunto das concretizações possíveis das ideias liberais" (Januzzi, 2006). No Brasil, esse movimento foi tímido, sendo o atendimento ao deficiente iniciado, provavelmente, por meio de Câmaras Municipais ou confrarias particulares (Januzzi, 2006). A literatura descreve o surgimento da educação especial por volta do século XVIII na Europa, voltada para o atendimento de surdos e cegos.

Na verdade, sob o manto da excepcionalidade são incluídos indivíduos com características as mais variadas, cujo ponto fundamental é o desvio 
da norma, não a norma abstrata, que determina a essência a-histórica da espécie humana, mas a norma construída pelos homens nas suas relações sociais. (SILVEIRA BUENO, 2004, p.64).

Para o autor, historicamente, o período que antecede o desenvolvimento da sociedade moderna pode ser considerado, para o atendimento ao deficiente, como um período extenso de gestação. O autor relata que, primeiramente, esses sujeitos foram subjugados a maus tratos e piedade, sendo que, posteriormente, essa situação tende a mudar quando são oferecidas oportunidades educacionais e de integração social. Nos tempos atuais, esse quadro passa por alterações significativas com a discussão e implementação de políticas de inclusão social.

Do conjunto de políticas vigentes no início do século $\mathrm{XX}$, surgem propostas que acabam por reforçar a separação entre normais e patológicos. São adotados critérios relacionados ao potencial cognitivo (grau de inteligência) para avaliação da anormalidade e, em consequência, a catalogação e categorização dos indivíduos. Passamos a ter não mais somente os deficientes orgânicos segregados como também surgiram categorias como "anormais intelectuais, morais e pedagógicos" (JANUZZI, 2006, p. 40). Conforme as categorias, os indivíduos seriam assistidos por profissionais específicos. É importante salientar que a responsabilidade direta pelo processo educacional desses indivíduos pertencia à classe médica. Em conjunto com os médicos e orientados por eles, os pedagogos agiam no processo educacional nos espaços instituídos fora do ambiente de educação formal.

\section{Inclusão escolar e paralisia cerebral}

Se para que a inclusão educacional de fato aconteça, é necessária a reorganização do pensamento e do funcionamento social e escolar, podemos dizer que, no caso da paralisia cerebral, conforme Rossi (1999), a concepção de educação das crianças tem passado por importantes modificações conceituais nas últimas décadas. Historicamente, o lugar dado à criança com paralisia cerebral foi a escola especial. A entrada delas na escola regular tem provocado reações diferenciadas, múltiplas interpretações e, às vezes, práticas pouco pedagógicas.

$\mathrm{Na}$ escola, as reações são bastante diversificadas, desde uma aceitação mais emotiva, cheia de pena e de sentimentos meio "melados" e superficiais que não devem durar muito ou serão prejudiciais ao desenvolvimento do aluno, até uma rejeição formal: "não temos 
condições nessa escola"; "Ele não vai acompanhar"; "Volte quando ele tirar a fralda" (só que ele é portador de uma mielomeningocele ou de uma paralisia cerebral grave, e não vai poder tirá-la, mas ninguém sabe disso na escola, nem cogita perguntar, informar-se). (MOURA, 2004, p. 400).

A falta de conhecimento, preparo e formação dos profissionais da educação, em muito, contribuem para o reforço da exclusão. Além disso, o que sabem sobre paralisia cerebral, muitas vezes, pertence ao campo do senso comum. Esse saber, fruto de um discurso socialmente produzido, costuma resultar na estigmatização e rotulação dos aprendizes. Por conseguinte, o sujeito passa a ser o culpado pelo seu fracasso.

Esse desconhecimento pelos educadores sobre o diagnóstico da criança com paralisia cerebral e suas repercussões no desenvolvimento neuropsicomotor, contribui em muito para reforçar o quadro de estigmatização social atual. Muitas confusões são feitas quanto aos diagnósticos. A mais comum delas é atribuir à criança com paralisia cerebral, com comprometimentos motores severos e comprometimentos de fala, por exemplo, a incapacidade mental. Como a criança apresenta dificuldade na linguagem expressiva, seja verbal ou não verbal, costuma ser estigmatizada e marginalizada no seu processo de aprendizagem e muitas vezes não aceita no espaço escolar regular, por a julgarem deficiente mental. Esse é apenas um dos possíveis exemplos em relação aos aspectos dificultadores da inserção e inclusão escolar dessas crianças.

Pesquisas (Ciasca, Moura-Ribeiro e Tabaquim, 2006) demonstram que as crianças com paralisia cerebral, além do déficit motor, apresentam outros déficits associados, como, por exemplo, visual, auditivo, de linguagem, de fala, viso espaciais, entre outros. No entanto, para definir se uma criança aprende ou não, é necessária a utilização de instrumentos que sejam capazes de avaliar o seu potencial cognitivo. Para isso, podem ser utilizados instrumentos formais de avaliação tanto qualitativos quanto quantitativos. É importante ressaltar que eles devem ser adequados aos objetivos e metas a serem atingidas, bem como adaptados às necessidades dos avaliados. Nesse sentido, inferimos que as escolas se encontram em condições precárias para avaliar. Além da falta de conhecimento dos docentes na área neuropsicológica, faltam à escola instrumentos adequados de avaliação.

Outro aspecto segregador no contexto escolar, de acordo com Moura (2004), é o modelo educacional competitivo. Crianças com comprometimentos motores importantes nem sempre são bem vindas a grupos de trabalho em sala de aula. A impressão que se tem é que o cognitivo somente se desenvolve se o motor funciona 
bem. Nesses casos, as aparências costumam enganar. Muitas dessas crianças costumam ter um desenvolvimento cognitivo compatível com sua faixa etária, uma ótima compreensão que os habilita a participar ativamente de diferentes contextos sociais, ressalvando as dificuldades motoras que exigirão uma maior atenção.

Podemos assim pensar que na sala de aula esses alunos deixam de participar de atividades devido aos seus limites motores. Os educadores, seja por desconhecimento teórico ou por inexperiência prática, costumam reproduzir modelos e elaborar ações pedagógicas que não contribuem para o processo de inclusão de crianças deficientes. No caso da paralisia cerebral, muitas vezes o comprometimento motor se torna déficit cognitivo e, por conseguinte, justificativa para o não-aprender da criança e álibi para equívocos pedagógicos.

\section{Método - modelo de investigação}

O estudo realizado adotou uma abordagem qualitativa. De acordo com Santos Filho e Gamboa (1995) e Bortoni-Ricardo (2008), a pesquisa qualitativa privilegia o entendimento da verdade como relativa e subjetiva e o entendimento da realidade como socialmente construída, compreendendo o homem como sujeito e ator dessa construção, e produto da interação. Como modelo de investigação adotamos a pesquisa-ação, uma vez que ela se caracteriza pelo uso de técnicas que evidenciam as mudanças da prática ao longo do processo investigativo (TRIPP, 2005). Salientamos que o estudo teve caráter longitudinal, sendo realizado ao longo do ano letivo com inserções semanais do pesquisador no campo pesquisado.

\section{Participantes}

A investigação foi realizada em escola pública na cidade de Ouro Preto, no estado de Minas Gerais (Brasil). A seleção dos participantes seguiu os seguintes critérios:

\footnotetext{
$\checkmark$ crianças com paralisia cerebral matriculadas nos anos iniciais do ensino regular $\checkmark$ possuir diagnóstico médico que comprove o comprometimento $\checkmark$ no caso da escola a mesma deverá ser pública $\checkmark$ no caso dos professores participam aqueles envolvidos diretamente com o processo de ensino da criança selecionada.
} 
Foram selecionadas duas crianças com paralisia cerebral, sendo uma com o quadro de hemiplegia espástica à direita e a outra com hemiplegia à esquerda. Ambas possuem 10 anos de idade e encontram-se cursando o $3^{\circ}$ ano do ensino fundamental $\mathrm{I}$. Serão aqui tratadas pelas siglas R. e V., como forma de preservar suas identidades. Foram selecionadas também duas professoras que acompanhavam diretamente o processo de aprendizagem dessas crianças. A criança com hemiplegia à esquerda apresentava dificuldades com interpretação textual, organização espacial, organização textual, cálculo matemático, dificuldade atencional, entre outros. Já a criança com hemiplegia à esquerda apresentava lentidão de movimentos e processamento de informação, dificuldade de concentração e manutenção do foco atencional, compreensão razoável de texto, porém com perda de informação quando o texto é longo, dificuldade de compreender sequência de comandos, entre outros.

\section{Percurso metodológico}

O pesquisador acompanhou a dinâmica da sala de aula uma vez por semana. Foram realizadas observações sobre o processo de aprendizagem das crianças com paralisia cerebral e das ações de ensino realizadas pelas professoras. Semanalmente os casos eram discutidos com as docentes na perspectiva de analisar os fatos e se pensar novas estratégias de ensino considerando os contextos analisados.

\section{Resultados e discussão}

Ao longo do ano letivo, podemos notar resultados positivos com relação à mudança na prática pedagógica das professoras, na concepção sobre a patologia e aprendizagem e na organização escolar como um todo.

Apresentamos abaixo um quadro que evidencia o processo de pesquisa e intervenção no cotidiano escolar. Nele relacionamos o fazer pedagógico já existente na escola, ou seja, a prática inicial do professor, as propostas de intervenção e a reelaboração das ações pedagógicas com base nas observações, análise e em experiências desenvolvidas em sala de aula. São quatro quadros organizados por temas. No primeiro estão os aspectos referentes ao conteúdo de leitura e escrita. No segundo estão aspectos do conteúdo de matemática, mais especificamente o cálculo matemático. O terceiro quadro representa dificuldades específicas de uma das crianças. Essas 
dificuldades se encontram no campo viso espacial. No último quadro encontram-se relacionados aspectos diversos do cotidiano da sala de aula e do processo de ensino e aprendizagem das duas crianças. Todos os quadros seguem a mesma sequência. Eles apresentam algumas características das crianças em relação aos seus comprometimentos, em seguida as estratégias criadas a partir das observações e discussões com as docentes e por fim os resultados das práticas reelaboradas em relação ao desempenho das alunas. 


\section{QUADRO 1 - Leitura e Escrita}

\begin{tabular}{|c|c|c|c|}
\hline Nomes & Antes das intervenções & Estratégias utilizadas - intervenções & Após as intervenções \\
\hline \multirow{2}{*}{ V. } & $\begin{array}{l}\text { Dificuldade de compreensão } \\
\text { textual - dificuldade em manter o } \\
\text { foco atencional. }\end{array}$ & $\begin{array}{l}\text { Trabalho com textos curtos; leitura em voz alta, por etapas: } \\
\text { parágrafo por parágrafo e com explicações extras e repetitivas, } \\
\text { além do fornecimento de direcionamentos específicos à } \\
\text { questão, ao assunto do texto. }\end{array}$ & $\begin{array}{l}\text { Consegue compreender o que está sendo dito nos textos ou } \\
\text { atividades, mesmo que gradualmente. }\end{array}$ \\
\hline & $\begin{array}{l}\text { Dificuldade com a escrita }- \\
\text { lentidão de movimento. }\end{array}$ & $\begin{array}{l}\text { Economia de escrita - entrega de cópias de materiais e } \\
\text { atividades prontas, para que a aluna não se canse apenas } \\
\text { copiando do quadro (quando a cópia não é o objetivo } \\
\text { primordial da tarefa). }\end{array}$ & $\begin{array}{l}\text { Sem a necessidade de copiar do quadro negro, a aluna se } \\
\text { dedica a outras tarefas da aula, como: tentar compreender } \\
\text { textos e atividades. }\end{array}$ \\
\hline \multirow{3}{*}{$\mathrm{R}$. } & $\begin{array}{l}\text { Dificuldade com a escrita }- \\
\text { lentidão de movimento. Copia do } \\
\text { quadro letra por letra. }\end{array}$ & $\begin{array}{l}\text { Economia de escrita - entrega de cópias de materiais e } \\
\text { atividades prontas para que a aluna não se canse apenas } \\
\text { copiando do quadro (quando a cópia não é o objetivo } \\
\text { primordial da tarefa). Estimular a cópia de palavras ou frases } \\
\text { inteiras do quadro, para que a aluna internalize e faça cópias } \\
\text { com mais agilidade. }\end{array}$ & $\begin{array}{l}\text { Sem a necessidade de copiar do quadro negro, a aluna se } \\
\text { dedica a outras tarefas da aula, como: fazer a leitura dos } \\
\text { textos e sua compreensão. Quando a cópia é necessária a } \\
\text { aluna a faz com um pouco mais de rapidez e autonomia, } \\
\text { copiando as palavras completas. }\end{array}$ \\
\hline & $\begin{array}{l}\text { Dificuldade em } \text { compreender } \\
\text { alguns conteúdos e informações } \\
\text { abstratas. }\end{array}$ & $\begin{array}{l}\text { Fornecimento de modelos concretos nas atividades. Ex. } \\
\text { material dourado; experimentos em sala; recursos visuais. }\end{array}$ & Compreende com mais facilidade e rapidez. \\
\hline & $\begin{array}{l}\text { Reversibilidade - não compreende } \\
\text { um processo inverso ao que é } \\
\text { apresentado no momento. Ex.: } \\
\text { destacar inicialmente palavras que } \\
\text { rimam (terminam com o mesmo } \\
\text { som) e em seguida, palavras que } \\
\text { iniciam com o mesmo som. }\end{array}$ & $\begin{array}{l}\text { Lembranças constantes do último comando para que a aluna } \\
\text { deixe de lado o que foi pedido anteriormente e atenda ao } \\
\text { pedido atual. }\end{array}$ & $\begin{array}{l}\text { Compreende e consegue retomar o comando atual e } \\
\text { devagar vai se acostumando com o novo pedido. }\end{array}$ \\
\hline
\end{tabular}

Fonte: autores 


\section{Quadro2: Cálculo}

\begin{tabular}{|c|c|c|c|}
\hline Nomes & Antes das intervenções & Estratégias utilizadas - intervenções & Após as intervenções \\
\hline \multirow{2}{*}{ V. } & $\begin{array}{l}\text { Dificuldade em resolver operações } \\
\text { matemáticas na horizontal. }\end{array}$ & $\begin{array}{l}\text { Trabalho com operações de matemática já armadas na vertical; } \\
\text { fazer os QVL's (Quadro Valor de Lugar) no caderno e/ou } \\
\text { entregar folhas A4 com QVL's para que a aluna apenas } \\
\text { preencha com os números. }\end{array}$ & $\begin{array}{l}\text { Não se frustra por não saber montar as operações, pois a } \\
\text { aluna já tem o modelo do quadro para ser apenas } \\
\text { preenchido por ela. Às vezes, não utiliza o quadro, pois } \\
\text { consegue montar a operação sem a limitação dos espaços } \\
\text { do QVL. }\end{array}$ \\
\hline & $\begin{array}{l}\text { Dificuldade em compreender as } \\
\text { operações de matemática - adição e } \\
\text { subtração; }\end{array}$ & $\begin{array}{l}\text { Trabalho com o concreto: material dourado, pauzinhos, } \\
\text { desenhos e dedos; explicações repetitivas sobre os objetivos das } \\
\text { contas (somar e tirar) e trabalho por etapas na resolução das } \\
\text { operações, para que fique memorizado parte por parte. }\end{array}$ & $\begin{array}{l}\text { Consegue resolver as operações sem o material dourado, } \\
\text { apenas com a memorização das etapas que precisam ser } \\
\text { seguidas para se chegar aos resultados. Às vezes é } \\
\text { necessário relembrar as etapas com a aluna. }\end{array}$ \\
\hline R. & $\begin{array}{l}\text { Dificuldade em compreender as } \\
\text { operações de matemática pela } \\
\text { condição de abstração. }\end{array}$ & $\begin{array}{l}\text { Trabalho com o concreto: material dourado, desenhos e dedos. } \\
\text { Uso de objetos para manusear. }\end{array}$ & $\begin{array}{l}\text { Consegue resolver as operações sem o material dourado, } \\
\text { às vezes utiliza risquinhos no caderno. }\end{array}$ \\
\hline
\end{tabular}

Fonte: autores 


\section{Quadro3: Viso espacial}

\begin{tabular}{|c|c|c|c|}
\hline Nomes & Antes das intervenções & Estratégias utilizadas - intervenções & Após as intervenções \\
\hline \multirow{3}{*}{ V. } & Não consegue interpretar gráficos. & $\begin{array}{l}\text { Trabalho com um modelo específico de gráfico por vez e } \\
\text { repetidas vezes, para que a aluna o compreenda e em seguida, } \\
\text { poder apresentar a ela outro tipo de gráfico, e assim } \\
\text { sucessivamente. }\end{array}$ & $\begin{array}{l}\text { Consegue compreender alguns modelos simples de } \\
\text { gráficos. }\end{array}$ \\
\hline & $\begin{array}{l}\text { Tem dificuldades para desenhar letras } \\
\text { como H minúsculo e Q maiúsculo. }\end{array}$ & $\begin{array}{l}\text { É mostrado a ela como se escreve no caderno e é colocada a } \\
\text { mão no lápis junto com a mão dela para que ela modele as } \\
\text { letras. }\end{array}$ & $\begin{array}{l}\text { Consegue desenhar ambas as letras, às vezes ela as } \\
\text { escreve toda torta, mas depois se corrige sozinha. Percebe } \\
\text { o erro gráfico. }\end{array}$ \\
\hline & $\begin{array}{l}\text { Dificuldade de lidar com atividades } \\
\text { longas, com muitas questões. }\end{array}$ & $\begin{array}{l}\text { Entrega de atividades menores, com poucas questões e menos } \\
\text { folhas, reorganizando visualmente o material impresso. }\end{array}$ & $\begin{array}{l}\text { Não se frustra perante as atividades, e consegue resolvê- } \\
\text { las de forma mais autônoma, mesmo que lentamente. }\end{array}$ \\
\hline
\end{tabular}

Fonte: autores 
Quadro 4: Diversos

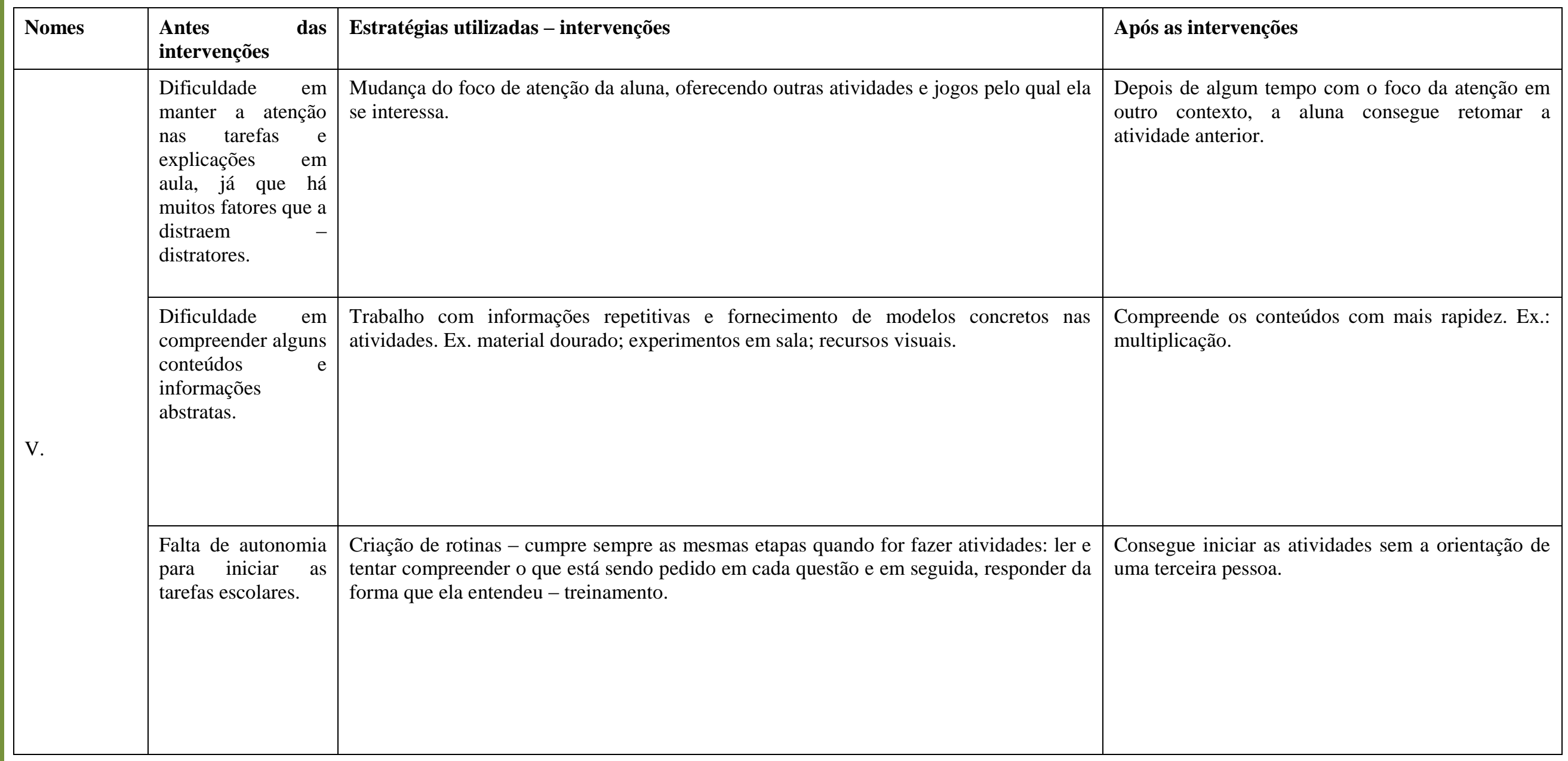




\begin{tabular}{|c|c|c|}
\hline $\begin{array}{l}\text { Dificuldade de } \\
\text { planejamento }- \text { de } \\
\text { cumprir fases para } \\
\text { se chegar ao } \\
\text { produto final. }\end{array}$ & $\begin{array}{l}\text { Trabalho por etapas: na compreensão textual; na resolução das operações matemáticas; } \\
\text { na rotina das atividades. }\end{array}$ & $\begin{array}{l}\text { Aos poucos, vai se acostumando com as rotinas de } \\
\text { organização das tarefas, mas ainda ela depende de } \\
\text { orientações da docente. }\end{array}$ \\
\hline $\begin{array}{l}\text { Desorganização do } \\
\text { material escolar na } \\
\text { carteira. }\end{array}$ & $\begin{array}{l}\text { Preparação de uma rotina de organização, em que os materiais são organizados todos os } \\
\text { dias ao chegar à aula, inicialmente com a ajuda da professora e de uma prancha de } \\
\text { comunicação. }\end{array}$ & $\begin{array}{l}\text { Não depende da professora para se organizar, já está } \\
\text { internalizado: chega à sala de aula e retira da } \\
\text { mochila apenas os materiais que serão utilizados no } \\
\text { momento. }\end{array}$ \\
\hline $\begin{array}{l}\text { Compara-se aos } \\
\text { colegas e por isso, } \\
\text { procura os erros e } \\
\text { defeitos dos outros } \\
\text { para não se sentir } \\
\text { inferiorizada. }\end{array}$ & $\begin{array}{l}\text { Trabalho contínuo e explicação de que todas as pessoas são passivas de erros. Trabalho } \\
\text { de autoestima. }\end{array}$ & $\begin{array}{l}\text { Hoje em dia, ela já não se preocupa tanto com os } \\
\text { colegas, busca se atentar com as suas próprias } \\
\text { tarefas. }\end{array}$ \\
\hline
\end{tabular}




\begin{tabular}{|c|c|c|c|}
\hline & $\begin{array}{lr}\text { Perde informações } \\
\text { pela agitação e } \\
\text { dificuldade } & \text { em } \\
\text { controlar } & \text { a } \\
\text { impulsividade. } & \end{array}$ & Lembranças contínuas de conteúdos já trabalhados anteriormente. & Consegue retomar os conteúdos, lentamente. \\
\hline \multirow[b]{4}{*}{ R. } & $\begin{array}{l}\text { Dificuldade me } \\
\text { manter informação } \\
\text { em memória de } \\
\text { curto prazo. }\end{array}$ & $\begin{array}{l}\text { Lembranças e pistas constantes de informações e conteúdos trabalhados nas aulas } \\
\text { anteriores. Procedimento de repetição. }\end{array}$ & $\begin{array}{l}\text { Consegue retomar os conteúdos já trabalhados e } \\
\text { prossegue compreendendo o assunto estudado. }\end{array}$ \\
\hline & $\begin{array}{l}\text { Cansaço excessivo, } \\
\text { em função das } \\
\text { alterações } \\
\text { neurológicas } \\
\text { (criança } \\
\text { bradcinética). }\end{array}$ & $\begin{array}{l}\text { Mudança de atividades para estimular sua participação; fornecimento de jogos } \\
\text { prazerosos ou a deixa descansar por alguns minutos. }\end{array}$ & $\begin{array}{l}\text { Depois da mudança de foco a aluna consegue } \\
\text { retomar a tarefa anterior com mais entusiasmo. }\end{array}$ \\
\hline & $\begin{array}{l}\text { Não compreende as } \\
\text { regras dos jogos e } \\
\text { por isso, não as } \\
\text { respeita. }\end{array}$ & $\begin{array}{l}\text { Trabalho realizado com o mesmo jogo repetidas vezes para que ela compreenda; } \\
\text { Flexibilidade - mudar as regras dos jogos para a aluna. }\end{array}$ & $\begin{array}{l}\text { Compreende mesmo que vagarosamente as regras } \\
\text { quando se pratica o mesmo jogo várias vezes e } \\
\text { participa com o restante da turma, sem se aborrecer. } \\
\text { Ex.: pular corda e pega-pega. }\end{array}$ \\
\hline & $\begin{array}{l}\text { Desorganização do } \\
\text { material escolar na } \\
\text { carteira. }\end{array}$ & $\begin{array}{l}\text { Preparação de uma rotina de organização, em que os materiais são organizados todos os } \\
\text { dias ao chegar à aula, inicialmente com a ajuda da professora e de uma prancha de } \\
\text { comunicação. }\end{array}$ & $\begin{array}{l}\text { Consegue se organizar sozinha, sem a ajuda de } \\
\text { terceiros. }\end{array}$ \\
\hline
\end{tabular}




\begin{tabular}{|c|c|c|}
\hline $\begin{array}{l}\text { Tem dificuldades } \\
\text { de manusear a } \\
\text { bolsinha de lápis de } \\
\text { cor que tem a } \\
\text { abertura muito } \\
\text { estreita e depende } \\
\text { da professora e dos } \\
\text { colegas para pegar } \\
\text { e guardar os lápis. }\end{array}$ & Foi pedido à sua mãe que conseguisse outra bolsinha, cuja abertura era mais larga. & $\begin{array}{l}\text { Com a nova bolsinha de lápis a aluna tem } \\
\text { autonomia para manusear os seus lápis. }\end{array}$ \\
\hline $\begin{array}{l}\text { Perde informações } \\
\text { pela lentidão de } \\
\text { processamento da } \\
\text { informação }\end{array}$ & $\begin{array}{l}\text { Lembranças consecutivas de conteúdos já trabalhados anteriormente. Atividade de } \\
\text { memória }\end{array}$ & Consegue retomar os conteúdos com facilidade. \\
\hline $\begin{array}{l}\text { Grande } \\
\text { dependência da } \\
\text { professora e dos } \\
\text { colegas para a } \\
\text { realização das } \\
\text { tarefas escolares. }\end{array}$ & $\begin{array}{l}\text { Rotina para a execução das tarefas, de modo que a aluna memorize as etapas das } \\
\text { atividades (leitura, entendimento e respostas) e as façam sozinha; Estimulação da } \\
\text { execução de tarefas sem a ajuda de terceiros. }\end{array}$ & $\begin{array}{l}\text { Ainda é dependente para a realização das atividades, } \\
\text { porém as estratégias continuam sendo feitas. Os } \\
\text { avanços têm acontecido de forma lenta. }\end{array}$ \\
\hline $\begin{array}{l}\text { Não participa } \\
\text { ativamente das } \\
\text { aulas, fica apenas } \\
\text { calada e sentada na } \\
\text { carteira. }\end{array}$ & $\begin{array}{l}\text { A aluna é envolvida nas atividades em sala de aula, é pedido a ela que fale suas respostas } \\
\text { e que vá ao quadro negro e resolva problemas matemáticos e outras atividades. }\end{array}$ & $\begin{array}{l}\text { Participa constantemente das aulas, por própria } \\
\text { vontade, e sempre pede à professora que a deixe } \\
\text { falar suas respostas. }\end{array}$ \\
\hline
\end{tabular}

Fonte: autores 
Inicialmente podemos refletir que a falta de conhecimento sobre a patologia pode implicar em ações cegas e intuitivas e na manutenção de modelos de homogeneização do processo de ensino, desconsiderando a diversidade e a necessidade de se pensar um fazer diferente do que costumeiramente se faz. Sabemos que há uma dificuldade, por parte de muitos docentes, em visualizar a diferença mesmo em turmas que não possuem alguma pessoa com deficiência. A manutenção de um fazer pedagógico automatizado denota a falta de conhecimento teórico-metodológico que não apenas contribui para a reprodução de modelos já existentes, como dificulta a adequação do ensino às novas demandas sociais.

Um primeiro avanço, nesse sentido, se dá no campo do conhecimento. Ter certa clareza sobre os limites e potenciais das crianças, com base no quadro da deficiência, resultou em estratégias que respeitassem o tempo de aprendizagem e a reorganização do modelo de ensino. Técnicas como a da economia de escrita, por muito não pensada na escola regular, passam a ser adotadas pelas docentes. A economia de escrita pressupõe uma mudança de foco entre privilegiar o ato motor da cópia, por exemplo, e o fornecimento de materiais prontos que viabilizem a aprendizagem. Para uma criança com lentidão de movimento e de processamento isso faz muita diferença. Permite a ela uma maior participação nos eventos da sala de aula e um maior sentimento de pertencimento àquele contexto.

Em relação às crianças, no que tange ao processo de leitura e escrita, podemos considerar que as práticas docentes iniciais se pautavam pela igualdade de ações no espaço da sala de aula. As crianças com paralisia cerebral passavam por processos de ensino pensados para os seus pares que não apresentam tal deficiência ou condição de aprendizagem. No caso de V. e R. podemos identificar dificuldades específicas no processo de leitura que exigem ações pedagógicas diferenciadas. Para V. a leitura se tornava difícil em função de alterações no campo viso espacial, na alteração comportamental (impulsividade), na dificuldade de manutenção da atenção, entre outros. À medida que essas alterações são observadas ao longo da pesquisa e novas estratégias são construídas, observamos uma mudança no comportamento e na produção da criança. Não temos um salto altamente qualitativo na aprendizagem, mas temos uma engrenagem que começa a se movimentar nesse sentido. Ao controlar um pouco mais o comportamento agitado e ao ver a diminuição de atividades de cópias do quadro, ao construir um esquema de leitura por partes menores do texto, a aluna conseguiu melhor desenvolver sua habilidade de compreensão textual. No caso da aluna R. a economia de 
escrita se fez fundamental. Por possuir lentidão de movimentos a criança demora por demais, a produzir qualquer texto. Sua cópia se dá letra a letra, o que inviabilizou a realização de outras atividades que exigiriam elaborações cognitivas mais aprimoradas. A aluna gastava todo o seu tempo, em sala de aula, realizando cópias e sendo negligenciada em seu potencial cognitivo. Ao diminuir o número de cópias e ao entregála atividades prontas para que apenas as respondesse, ela passou a ganhar agilidade e a participar de forma mais efetiva do contexto da sala de aula.

Quanto ao cálculo, observamos que V. em função das desordens viso espaciais apresenta maior dificuldade na organização espacial das operações matemáticas e, por conseguinte, na resolução das mesmas. Ter detectado isso possibilitou a reorganização das suas ações e estratégias. A intervenção junto à docente e à criança foi no sentido de organizar esquemas gráficos para a realização de cálculo. Vale ressaltar que V. não realiza cálculo mental com facilidade, necessitando de materiais concretos que a auxiliem. A estratégia de escrever/desenhar nas folhas em branco quadros posicionais e quadrados para que ela colocasse os números nesses espaços foi de grande ajuda. Isso deu maior velocidade à criança que passou a operar com maior entusiasmo e fluidez. Já para R. a estratégia teve que ser diferente, pois sua necessidade ainda se encontra no pensamento operatório-concreto (Papalia, Olds, Feldman, 2006) .

Por fim, analisar as demais dificuldades e as potencialidades se torna importante, uma vez que elas interferem diretamente no processo de aprendizagem das crianças. A identificação e observação desses aspectos foi de fundamental importância para a reelaboração de estratégias pedagógicas que viabilizassem a melhoria do processo de ensino e de aprendizagem. Ao considerar a lentidão de processamento e de movimento de R. foi possível intervir na sua produção escrita em sala de aula. Quando a docente passa a perceber que a produção escrita está comprometida em função das alterações neurológicas da criança ficou mais fácil de se pensar na necessidade de reorganizar a forma de ensino para essa criança. Quando a demanda se tornou mais explícita e compreendida, a ação se fez reelaborar. Isso significa que a docente teve que refazer a sua concepção de ensino e de aprendizagem diante da situação que emergia ali, em sala de aula. Como resultado temos uma aluna mais participativa, mais envolvida com sua aprendizagem e mais interessada ante a uma aluna anteriormente desmotivada. No caso de V. não foi diferente. Um exemplo simples desse caso pode ser dado a partir da construção de rotina de organização. Uma vez detectado a dificuldade de organização espacial, foram construídas rotinas que contribuíssem para que a criança se organizasse 
e ganhasse autonomia. Essa organização interferiu diretamente no seu comportamento, na diminuição da agitação e em maior concentração nas atividades. Com a redução da quantidade de atividades, estratégias de leitura de texto por partes menores, entre outras, ela, assim como R., evidenciou maior envolvimento e autonomia.

Nesse sentido, podemos inferir que possibilitar a participação dos diferentes como diferentes é um reforçador dos ideais de cidadania e de respeito às diversidades. Quando os docentes começam a introduzir em suas práticas outras práticas não permitidas ou não cultuadas no santuário escolar provocam deslocamentos importantes e evidenciam a possibilidade das interações funcionais (TRILLA, 2006). Entendemos aqui que a compreensão do diagnóstico e a construção de uma estrutura de ensino com base nessa compreensão e com vistas à promoção da aprendizagem, considerando a especificidade do caso, pode promover um salto de qualidade na relação ensinoaprendizagem. Por conseguinte, poderemos ter docentes mais qualificados para a atuação pedagógica (Nóvoa, 2009) e crianças com deficiências sendo compreendidas na sua diferença e não na sua igualdade ou na busca de sua normalidade.

A sensação que se tem é que, embora o que a educação possa oferecer ao sujeito seja mostrar-lhe o que é capaz de transformar e não somente reproduzir, o que de fato se vê é que os modelos tradicionais de ensino têm se preocupado muito mais com a reprodução e a perpetuação desses modelos (ESTEVES; MONTEMÓR, 2011). Nesse sentido, a investigação aqui apresentada nos abre possibilidades de compreender o fenômeno da inclusão em outra perspectiva. Perspectiva essa que considera o contexto escolar, o fazer pedagógico o cotidiano do docente e do aluno, bem como os saberes externos e aqueles produzidos in loco.

\section{Considerações}

O presente trabalho partiu do pressuposto que a ação docente, e as estratégias de ensino geralmente desenvolvidas pelos professores, em muito têm se distanciado das necessidades educacionais manifestadas pelas crianças com deficiência. Muitas dessas crianças têm apenas ocupado espaços físicos em sala de aula. Compreender as necessidades e demandas desses alunos é primordial para se pensar as ações pedagógicas adequadas ao seu processo e etapa de desenvolvimento e aprendizagem. 
Constatamos que o processo de observação, análise e intervenção proposto pelo modelo de pesquisa implicou em resultados positivos para o grupo de pessoas envolvidas. Esses resultados provocaram um movimento na escola que influenciou a rotina dos professores, bem como no repensar de suas ações. Por outro lado, entendemos que todo processo de mudança é lento e precisa ser reforçado, reconstruído sempre. Aqui apresentamos alguns casos que não retratam toda a realidade existente. Sabemos que as demandas são muitas e que as formas de lidar com elas são diversas. No entanto, apontamos possibilidades de se refletir e pensar ações que possam atender a diversidade que temos e precisamos enfrentar.

Entendemos ainda que o debate sobre a inclusão precisa ir para além do campo teórico e acadêmico e entrar nos contextos em que de fato acontecem, no caso, as escolas e salas de aula. As crianças com deficiência que se encontram matriculadas na rede de ensino regular precisam ser atendidas na sua diversidade. Para tanto, é necessário que o professor tenha conhecimentos para compreender essa diversidade, compreender o processo de aprendizagem desse sujeito e pensar a sua atuação pedagógica diante dessa realidade. Nesse sentido é que entendemos que o acompanhamento do cotidiano do professor e a possibilidade de pesquisas que analisem esse cotidiano e construam novos olhares juntamente com os professores podem trazer algum diferencial para a prática inclusiva.

\section{REFERÊNCIAS}

BORTONI-RICARDO, Stella Maris. O professor pesquisador: introdução à pesquisa qualitativa. São Paulo: Parábola Editorial, 2008.

CIASCA, S.M.; MOURA-RIBEIRO, M.V.L. De; TABAQUIM, M.L.M. Aprendizagem e paralisia cerebral. In: ROTTA, N. T. et al. Transtornos de aprendizagem: Abordagem neurobiological e multidisciplinar. Porto Alegre: Artmed, 2006.

ESTEVES, P. E. do C. C., MONTEMÓR, H. A. de S. M. Uma proposta de educação não-formal: o Espaço da Criança Anália Franco. Educação em Revista, Marilia, 12 (2), p.109-134, 2011.

JANNUZZI, Gilberta S. de M. A educação do deficiente no Brasil: dos primórdios ao início do século XXI. 2 ed. Campinas, SP: Autores associados, 2006. 
LEITE, Jaqueline M.R.S.; \& PRADO, Gilmar F.do. Paralisia Cerebral: Aspectos fisioterapêuticos e Clínicos. Revista Neurociências. 12 (1), 41-45, 2004.

MANTOAN, Maria T. E. Inclusão escolar: O que é? Por quê? Como fazer? (2. ed.). São Paulo: Moderna, 2006.

NÓVOA, António. Professores imagens do futuro presente. Lisboa. Educa, 2009.

PAPALIA, Diane E.; OLDS, Sally W.; FELDMAN, Ruth D. Desenvolvimento Humano. Trad. Carla Filomena M. P. Vercesi et.al. 10ed., Porto Alegre, 2010.

ROSSI, Luciana S. P. A. Os caminhos e descaminhos da educação da criança com paralisia cerebral: pais - crianças - professores. Dissertação de Mestrado, Centro Sarah de Formação e Pesquisa da USCR, Brasília, 1999.

SANTOS FILHO, J.C.; GAMBOA, S.S.(Orgs.). Pesquisa educacional: quantidadequalidade. São Paulo: Cortez, 1995.

SILVA, Jerusa P.T. Escola Plural e Educação Inclusiva: diversos olhares, múltiplos sentidos. Dissertação de Mestrado, Faculdade de Educação da UFJF, Juiz de Fora, 2005.

BUENO, J. G. S. Educação especial brasileira: integração/segregação do aluno diferente. (2 ed.). São Paulo: EDUC, 2004.

SIMÕES, Eneida Fonseca. Atendimento escolar no ambiente hospitalar. (2ed.). São Paulo: Memnon, 2008.

TRILLA, Jaume. A educação não-formal. In: V. A. Arantes (Org.). Educação formal e não-formal: pontos e contrapontos. São Paulo: Summus, 2008.

TRIPP, David. Pesquisa-ação: uma produção metodológica. Lolio Lourenço de Oliveira (Trad.). Educação e Pesquisa, São Paulo, 31 (3), 443-466, set/dez 2005.

UNESCO. Declaração de Salamanca e linha de ação sobre necessidades educativas especiais. Brasília, CORDE, 1994.

\section{Como referenciar este artigo}

FRANCO, Marco Antônio Melo.; RODRIGUES, Paloma Roberta Euzebio. O fazer pedagógico em contexto de inclusão: estratégias, ações e resultados). Revista IberoAmericana de Estudos em Educação, Araraquara/SP, v. 11, n. 3, p.1184-1197, 2016. Disponível em: <https://dx.doi.org/10.21723/riaee.v11.n3.7481>. E-ISSN: 1982-5587.

Submetido em: 27/01/2015

Aprovação Final em: 29/07/2016 